\title{
ĐÁNH GIÁ RỦI RO CHO HỆ THỐNG HỒ CHỨA BẬC THANG TRỀ SÔNG ĐÀ KHI CÓ SỰ CỐ VÕ̃ ĐẬP
}

\author{
Lê Văn Nghị ${ }^{1}$
}

Tóm tắt: Sông Đà là nhánh lớn nhất của hệ thống sông Hồng, có tiềm năng thủy điện vào bậc nhất cả nước. Trên lưu vưc sông Đà trong lãnh thổ Việt Nam đã xây dựng 7 hồ chứa lớn, trong đó có 3 công trình thưy điện lớn nhất Việt Nam là Lai Châu, Sơn La và Hòa Bình. Các hồ chứa bậc thang này có nhiệm vu quan trọng trong chống lũ, cấp nước tưới và phát điện nhưng đồng thời mối công trình đều làm tăng thêm những rủi ro tiềm ẩn cho hệ thống và công trình bậc dưới nếu gặp sự cố. Bài báo trình bày kết quả đánh giá rủi ro cho hệ thông các công trình hồ chứa bậc thang sông Đà theo các kịch bản sự cố võ đập bằng mô hình toán thủy lực. Kết quả đánh giá là co sở để các nhà quản lý, quy hoạch và nghiên cưu vận hành hợp lý các hồ chứa bậc thang sông Đà cũng nhu đảm bảo an toàn cho hạ du sông Hồng.

Từ khóa: Mô hình toán, Hồ chưa bậc thang, Sông Đà, Vỡ đập.

Ban Biên tập nhận bài: 24/01/2019 Ngày phản biện xong: 15/03/2019 Ngày đăng bài: 25/04/2019

\section{Mở đầu}

Sông Đà là chi lưu lớn nhất của hệ thống sông Hồng, bắt nguồn từ vùng núi Ngụy Sơn (Trung Quốc) chảy vào nước ta tại Mường Tè, Lai Châu theo hướng Tây Bắc - Đông Nam. Tổng lượng dòng chảy sông Đà chiếm hơn $50 \%$ tổng lượng dòng chảy sông Hồng. Với địa hình có độ dốc lớn, nhiều công trình hồ chứa được xây dựng trên sông Đà nhằm phòng chống lũ, cung cấp nước tưới, phục vụ giao thông thủy và đặc biệt là đóng góp một phần rất lớn cho tổng năng lượng điện toàn quốc. Sông Đà trong lãnh thổ Việt Nam hiện có 7 công trình hồ chứa lớn gồm Lai Châu, Sơn La, Hoà Bình trên dòng chính và Bản Chát, Huội Quảng, Nậm Mu, Nậm Chiến trên các dòng nhánh (Hình 1)

Các hồ chứa lớn và rất lớn với dung tích hàng chục tỷ mét khối cùng hệ thống đê làm nhiệm vụ cắt lũ chu kỳ 500 năm cho Hà Nội. Tuy nhiên nếu xảy ra lũ lớn hơn cho Hà Nội lũ lớn hơn tần suất này thì vẫn gây lo lắng cho các nhà khoa học

IPhòng Thí nghiệm trọng điểm Quốc gia về động lực học sông biển

Email: levannghi@gmail.com và quản lý với giả định những tình huống bất ngờ xảy ra. Cùng với quá trình phát triển kinh tế xã hội, sự biến đổi cực đoan của thời tiết khiến chúng ta cần lường trước nguy cơ rủi ro do vỡ đập [3].

Vỡ đập là hiện tượng không mong muốn nhưng đã có nhiều đập bị vỡ do các nguyên nhân khác nhau trong khi tích nước và cả trong giai đoạn thi công. Ở Việt Nam đã ghi nhận được các sự cố vỡ đập như: hồ Đầm Hà (Quảng Ninh, 2014), vỡ toàn bộ đập phụ; hồ Hố Hô (Hà Tĩnh, 2013), nước tràn qua đỉnh đập; hồ Đồng Đáng, Khe Luồng (Thanh Hóa, 2013); hồ Cửa Đạt (2007), vỡ đập tràn xây dở; hồ Suối Hành (Khánh Hòa, 1986); hồ Yên Lập (Quảng Ninh, 1982); hồ Sông Mực, hồ Nam Thạch Hãn (19811982); hồ Suối Trầu (1978) [3]... Trên thế giới đã xảy ra vỡ Đập Lawn (Mỹ, 1982); đập Âm Dương Khỏa (Trung Quốc, 1983); đập Malpaset (Pháp, 1959), đập Barna ở Ấn Độ... [1].

Các hồ chứa bậc thang sông Đà có tính chất quan trọng về cả kinh tế, xã hội và chính trị nên trong quá trình quy hoạch, xây dựng và khai thác vận hành đã được quan tâm nghiên cứu. Bài toán 
về vỡ đập trên sông Đà đã được tập trung tính toán trong giai đoạn nghiên cứu khả thi Thủy điện Sơn La khoảng 20 năm về trước, bởi nhiều cơ quan tư vấn và nghiên cứu. Điển hình là các nghiên cứu của Lê Trần Chương, Lê Văn Thuận, Vũ Anh Khoa (1997) [2], Nguyễn Viết Phách và cs. (1998); Nguyễn Văn Hạnh và cs. (2003) [4], Trần Đình Hợi và cs. (2004) [5], Trần Thục (2003) [7]... Các nghiên cứu này tập trung đánh giá ảnh hưởng của sự cố vỡ đập Sơn La đến an toàn của hồ Hòa Bình và đồng bằng Bắc Bộ. Các hồ chứa được đưa vào tính toán chỉ gồm 3 hồ trên dòng chính sông Đà là Lai Châu, Sơn La và Hòa Bình, riêng hồ Sơn La được tính toán xem xét với các quy mô công trình Sơn La cao, thấp và trung bình. Bên cạnh đó công cụ tính toán còn hạn chế về mô phỏng điều hành hồ, lũ tràn đồng, các kịch bản tính toán.

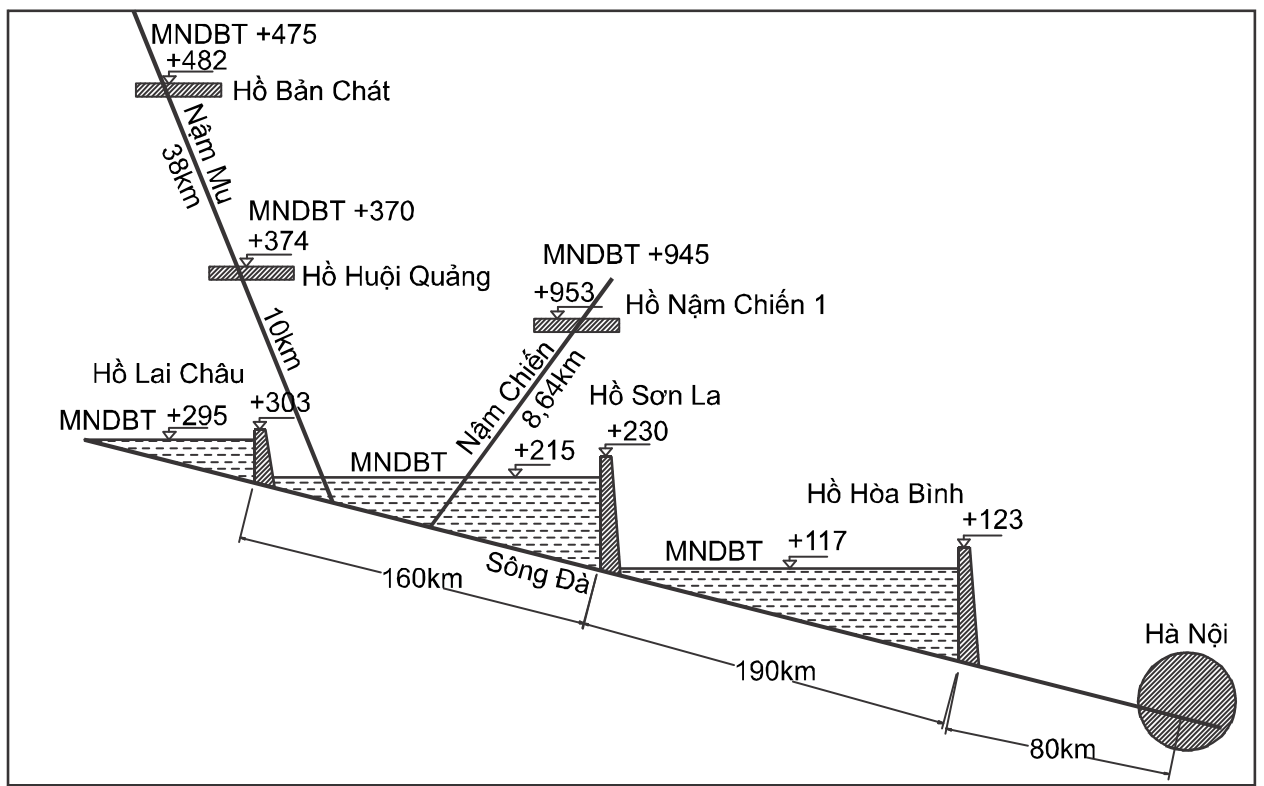

Hình 1. So đồ bậc thang hồ chứa lưu vực sông Đà

Bảng 1. Thông số các hồ chưa lớn trên hệ thống sông Đà

\begin{tabular}{|c|c|c|c|c|c|c|c|}
\hline Tên thông số & $\begin{array}{l}\text { Lai } \\
\text { Châu }\end{array}$ & $\begin{array}{c}\text { Sơn } \\
\mathrm{La}\end{array}$ & Hòa Bình & $\begin{array}{l}\text { Bản } \\
\text { Chát }\end{array}$ & $\begin{array}{l}\text { Huội } \\
\text { Quảng }\end{array}$ & $\begin{array}{c}\text { Nậm } \\
\text { Chiến } 1\end{array}$ & $\begin{array}{c}\text { Nậm } \\
\text { Chiến } 2\end{array}$ \\
\hline 1. Trên sông & Đà & Đà & Đà & $\begin{array}{l}\text { Nậm } \\
\mathrm{Mu}\end{array}$ & $\begin{array}{l}\text { Nậm } \\
\mathrm{Mu}\end{array}$ & $\begin{array}{l}\text { Nậm } \\
\text { Chiến }\end{array}$ & $\begin{array}{l}\text { Nậm } \\
\text { Chiến }\end{array}$ \\
\hline $\begin{array}{l}\text { 2. Dung tích toàn bộ hồ chứa } \\
\text { ứng với đỉnh đập }\left(10^{6} \mathrm{~m}^{3}\right)\end{array}$ & 1215 & 9260 & 9450 & 2137,7 & 184,2 & 154,75 & 3,7 \\
\hline 3. Dung tích phòng lũ $\left(10^{6} \mathrm{~m}^{3}\right)$ & 0 & 4000 & 5600 & & & & \\
\hline 4. Cao trình đỉnh $(\mathrm{m})$ & 303 & 228.1 & 123 & 482 & 374 & 953 & 275 \\
\hline 5. Chiều cao đập lớn nhất (m) & 137 & 138.1 & 128 & 130 & 104.4 & 135 & $49 / 53$ \\
\hline 6. Chiều dài đập theo đỉnh (m) & & 860 & & 424.45 & 267 & 273.3 & $50.6 / 38.75$ \\
\hline 7. Lưu lượng thiết kế $\left(\mathrm{m}^{3} / \mathrm{s}\right)$ & 20730 & 38240 & 37800 & 8382 & 10883 & & \\
\hline 8. Lưu lượng kiểm tra $\left(\mathrm{m}^{3} / \mathrm{s}\right)$ & 27452 & & & 10059 & 12908 & 2456.7 & 2351 \\
\hline 9. Mực nước trước lũ (m) & 295 & 194 & 101 & & & & \\
\hline $\begin{array}{l}\text { 10. Mực nước dâng bình thường } \\
\text { (m) }\end{array}$ & 295 & 215 & 117 & 475 & 370 & 945 & 272 \\
\hline 11. Mực nước lũ lớn nhất (m) & 302,95 & 228,07 & 122,07 & 479,68 & & 950,73 & 272,77 \\
\hline
\end{tabular}


Bài báo trình bày kết quả nghiên cứu trên mô hình toán thủy lực, đánh giá rủi ro cho hệ thống hồ chứa bậc thang theo các kịch bản xảy ra sự cố vỡ đập trên sông Đà trong điều kiện các công trình trên bậc thang đã hoàn chỉnh, một cách có hệ thống xét đến các rủi ro có thể xảy ra đối với hệ thống hồ chứa trên sông Đà. Nghiên cứu đã sử dụng mô hình MIKE để mô phỏng hệ thống hồ chứa bậc thang trên sông Đà, ứng dụng module DamBreak để mô phỏng vỡ đập, vết vỡ của đập Hòa Bình sử dụng từ kết quả mô phỏng trên mô hình vật lý [3] [6] cung cấp một cách hệ thống các kịch bản sự cố có thể xảy ra, hiệu quả làm việc của các hồ (thông số mực nước, lưu lượng xả lũ).

\section{Mô hình tính toán}

Mô hình toán thủy lực MIKE của DHI [8] có khả năng tính toán diễn biến dòng chảy theo không gian và thời gian. Mô hình lũ sự cố vỡ đập được xây dựng trên phần mềm MIKE 11.

Vùng mô phỏng bao gồm toàn bộ sông Đà từ biên giới Việt Trung đến ngã ba Thao - Đà và nhánh Nậm $\mathrm{Mu}$, Nậm Chiến. Các nhánh sông, suối khác được mô phỏng là các biên gia nhập khu giữa. Các hồ được đưa vào tính toán gồm Lai Châu, Sơn La, Hòa Bình, Bản Chát, Huội Quảng, Nậm Chiến 1 và Nậm Chiến 2 (Hình 1). Tài liệu địa hình lòng dẫn là số liệu đo năm 2013, riêng sông Đà đo năm 2014. Các thông số công trình lấy theo quy trình vận hành liên hồ chứa [9]. Biên nhập lưu của mô hình là các đường quá trình lưu lượng theo thời gian $\mathrm{Q}(\mathrm{t})$ nhập vào sông chính. Biên dưới của mô hình do không khảo sát quá trình lũ hạ lưu nên được cho là hằng số.

Hệ thống hồ chứa trên bậc thang sông Đà được thiết lập là các công trình nối tiếp, dung tích hồ chứa được mô phỏng là lòng dẫn sông. Do sự sai khác của lòng dẫn và lòng hồ thực tế, nên dung tích hồ được bổ sung vào dạng ô chứa lũ trên sông, đặc biệt với hồ Sơn La, Hòa Bình và Bản Chát. Quan hệ dung tích cao trình được lấy theo báo cáo thẩm định an toàn đập Hòa Bình năm 2013. Tại các vị trí đập dâng các công trình tháo được thiết lập trên các nhánh song song: gồm tràn xả mặt, tràn xả đáy, nhà máy thủy điện, công trình vỡ đập. Các công trình có cửa van được thiết lập là công trình điều khiển (Bảng 1).

Bảng 2. Các công trình điều khiển trên hệ thống bậc thang sông Đà

\begin{tabular}{ccccccc}
\hline TT & $\begin{array}{c}\text { Tên } \\
\text { nhánh sông }\end{array}$ & $\begin{array}{c}\text { Tọa } \\
\text { độ }\end{array}$ & $\begin{array}{c}\text { Tên } \\
\text { công trình }\end{array}$ & $\begin{array}{c}\text { Dạng } \\
\text { điều khiển }\end{array}$ & $\begin{array}{c}\text { Hệ số } \\
\text { lưu lượng }\end{array}$ & $\begin{array}{c}\text { Tốc độ } \\
\text { mở cửa van }\end{array}$ \\
\hline 1 & Son La Sluice & 250 & SL Xa day & Underflow & 0,74 & 0,0034 \\
2 & SONGDA & 279250 & SL Xa mat & Underflow & 0,74 & 0,005 \\
3 & SONGDA & 102500 & LC Xa mat & Underflow & 0,76 & 0,007 \\
4 & Lai Chau Xa day & 250 & LC Xa day & Underflow & 0,76 & 0,005 \\
5 & NamMu & 78400 & BC Xa mat & Underflow & 0,69 & 0,01 \\
6 & NamMu & 101400 & HQ Xa mat & Underflow & 0,69 & 0,005 \\
7 & HBSluice & 250 & HB Xa day & Underflow & 0,76 & 0,005 \\
8 & SONGDA & 473300 & HB Xa mat & Underflow & 0,69 & 0,005 \\
9 & NamChien & 41500 & NC2 Xa mat & Underflow & 0,67 & 0,003 \\
\hline
\end{tabular}

Các giả thiết trong quá trình nghiên cứu:

- Không xét quá trình biến động lòng dẫn khi xảy ra lũ vỡ đập. Chỉ xét quá trình phát triển (biến đổi) của lỗ vỡ.

- Các vết vỡ của đập bê tông được giả thiết là vỡ theo từng khoang, với chiều rộng là bội số của chiều rộng 1 khối đổ giữa hai khe lún của đập, được lấy là $20 \mathrm{~m}$, tại vị trí $2 / 3$ chiều cao đập, các trường hợp vỡ đập là tràn đỉnh với cột nước cao $2 \mathrm{~m}$.

- Lỗ vỡ của đập Hòa Bình được lấy theo kết quả thí nghiệm trên mô hình vật lý.

- Hồ được coi là bị vỡ khi có nước tràn đỉnh với độ cao $2 \mathrm{~m}$. Khi mực nước hồ chưa đến ngưỡng gây vỡ (tràn đỉnh dưới $2 \mathrm{~m}$ ) thì dòng qua đỉnh tính như một đập tràn. 


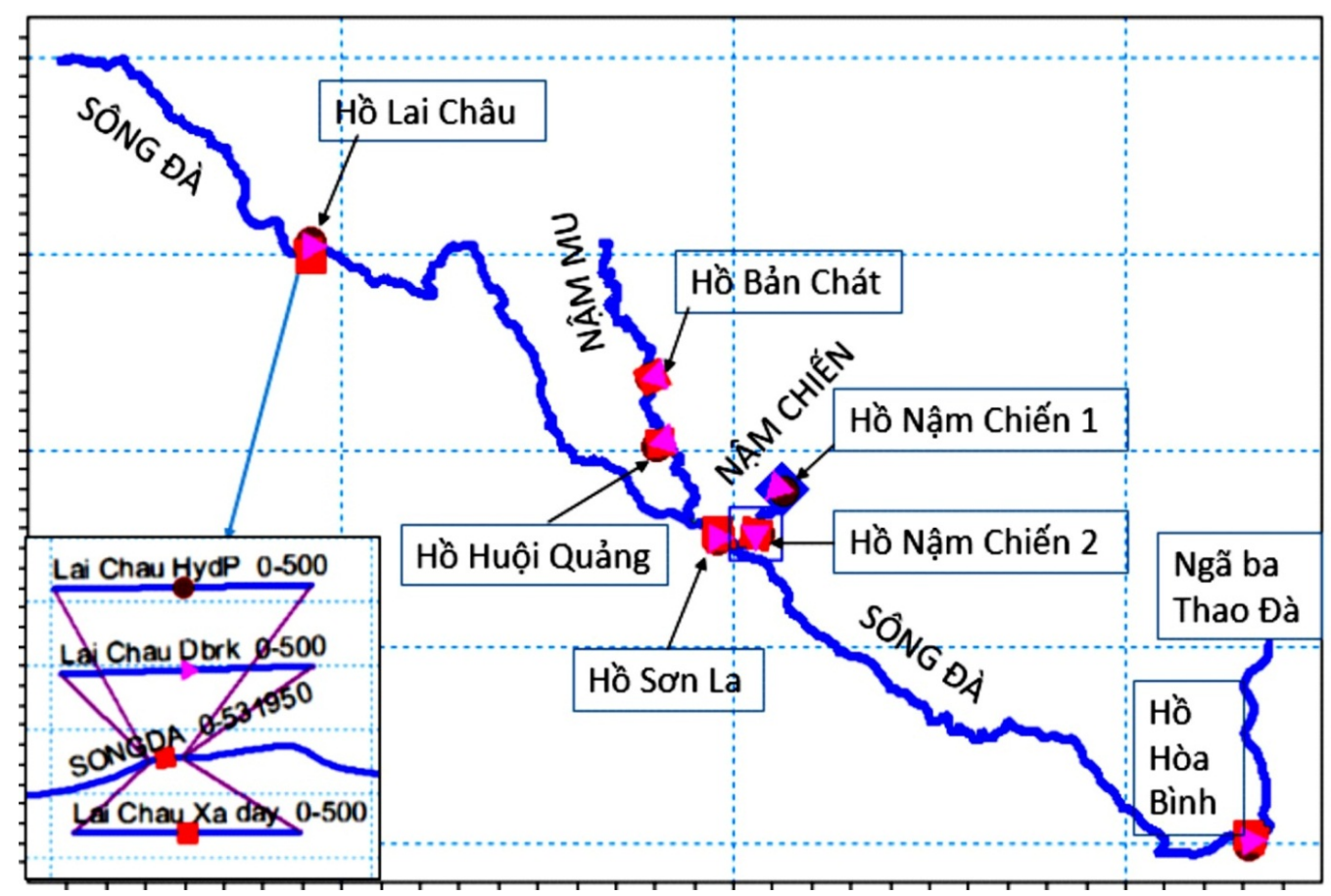

Hình 2. Vị trí hệ thống hồ mô phỏng trong so đồ mạng sông thuỷ lục 1 chiều

\section{Kết quả tính toán các kịch bản vỡ đập}

\subsection{Các kịch bản tính toán}

Với mô hình lũ 500 năm đến hồ Hòa Bình được phân bổ theo diện tích lưu vực đến các điểm khống chế cho các hồ là tuyến đập. Các hồ vận hành bình thường trong các trường hợp đảm bảo cắt lũ cho hạ du. Từ đó kích hoạt vỡ đập với trường hợp tràn đỉnh hoặc sự cố thân đập (đập Hòa Bình). Thiết lập 42 kịch bản vỡ đập trên hệ thống bậc thang sông Đà từ vỡ riêng lẻ tới vỡ hệ thống và 162 trường hợp vỡ hồ Sơn La và vỡ đập do ẩn họa trong thân đập, tổng hợp thành 8 nhóm kịch bản vỡ đập do tràn đỉnh cụ thể như sau:

1. Nhóm kịch bản vỡ đập trên dòng chính sông Đà:

- Nhóm kịch bản 1 (KB1), vỡ toàn bộ hệ thống hồ thượng lưu hồ Lai Châu, thuộc lãnh thổ Trung Quốc. Do không có số liệu cụ thể của các hồ này nên nghiên cứu lựa chọn trường hợp bất lợi nhất là coi tổng dung tích các hồ dồn xuống một hồ bậc cuối cùng. Xét với 03 kịch bản mực nước hồ tại thời điểm vỡ gồm: mực nước trước lũ (MNTL) - KB1.0, các hồ hạ lưu ở mực nước dâng bình thường (MNDBT) - KB1.1 và mực nước lũ thiết kế (MNLTK) - KB1.2. Trong mỗi kịch bản mực nước lại xét kịch bản về dung tích hồ ở thượng lưu Lai Châu. Khi mực nước các hồ là MNTL, xét với dung tích hồ lần lượt là: $\mathrm{W}=$ $2,0,2,5$ và 5,0 tỷ $\mathrm{m}^{3}$ tương ứng các kich bản KB1.0.a, KB1.0.b và KB1.0.c. Tổng số nhóm này có $9 \mathrm{~KB}$;

- Kịch bản vỡ đập Lai Châu, gồm 3 kịch bản tổ hợp mực nước hồ Hòa Bình, Sơn La khác nhau (nhóm KB2). Khi vỡ hồ Lai Châu, các hồ còn lại đang ở: MNTL - KB2.0, MNDBT KB2.1 và MNLTK - KB2.2;

- Kịch bản vỡ Sơn La, gồm 3 kịch bản với các tổ hợp bề rộng vết vỡ khác nhau $(\mathrm{B}=60 \mathrm{~m} ; 20 \mathrm{~m})$ và mực nước hồ Hòa Bình (nhóm KB6). Cụ thể như sau: KB6.0 - vỡ đập Sơn La 60m, các hồ ở MNTL; KB6.1 - vỡ đập Sơn La 60m, các hồ ở mức MNDBT và KB6.2 - vỡ đập Sơn La 20m, các hồ ở mức MNDBT.

2. Nhóm kịch bản vỡ đập trên nhánh Nậm $\mathrm{Mu}:$

- Kịch bản vỡ đập Bản Chát, gồm 3 kịch bản tổ hợp mực nước hồ Hòa Bình, Sơn La khác nhau (nhóm KB3);

- Kịch bản vỡ đập Huội Quảng, gồm 3 kịch bản tổ hợp mực nước hồ Hòa Bình, Sơn La khác nhau (nhóm KB4).

3. Nhóm kịch bản vỡ đập trên nhánh Nậm 
Chiến: (hồ Nậm Chiến 1, Nậm Chiến 2) ứng với 3 kịch bản tổ hợp mực nước hồ Hòa Bình, Sơn La khác nhau (nhóm KB5);

4. Nhóm kịch bản đồng thời vỡ đập Lai Châu, Bản Chát, Huội Quảng, Nậm Chiến 1 và Nậm Chiến 2, gồm 3 kịch bản tổ hợp mực nước hồ Hòa Bình, Sơn La khác nhau (nhóm KB7);

Mỗi nhóm KB: 3, 4, 5, 7 gồm $03 \mathrm{~KB}$ nhu KB2.

Bài báo trình bày kết quả tính toán giả định sự cố vỡ đập các hồ chứa bậc thang sông Đà ảnh hưởng đến hồ chứa hạ lưu, là các nhóm kịch bản từ KB1 đến KB7. Chi tiết các kịch bản xem trong [6]. Khi kích hoạt vỡ đập theo các kịch bản thì hệ thống các hồ khác vận hành bình thường theo quy định tại quy trình liên hồ chứa [9] mà chưa xét đến trường hợp điều tiết cắt giảm lũ cho hạ du hoặc đảm bảo an toàn hồ phía dưới.

\subsection{Kịch bản võ̃ đập trên dòng chính sông Đà}

1. Vỡ các hồ thượng lưu Lai Châu (KB1)

Khi xảy ra sự cố vỡ đập trên thượng lưu Lai Châu (các hồ phía Trung Quốc), giả thiết các kịch bản tổng lượng lũ vỡ đập là $\mathrm{W}=2,0$ tỷ $\mathrm{m}^{3}$,
2,5 tỷ $\mathrm{m}^{3}$ và 5,0 tỷ $\mathrm{m}^{3}$ tương ứng khi đó hồ Lai Châu đang ở MNDBT (+295,0m) hoặc MNLTK $(+297,9 m)$. Theo kết quả tính toán lưu lượng đỉnh lũ sinh ra do vỡ đập (theo công thức Floehlich) tương ứng là $39.300 \mathrm{~m}^{3} / \mathrm{s}, 41.200 \mathrm{~m}^{3} / \mathrm{s}$ và $49.800 \mathrm{~m}^{3} / \mathrm{s}$. Kết quả tính toán thể hiện trên Bảng 2, Hình 2.

Khi xảy ra sự cố vỡ đập trên hệ thống hồ chứa thượng lưu Lai Châu với kịch bản tổng dung tích của các hồ là 2,0 tỷ $\mathrm{m}^{3}$ (KB1.a), 2,5 tỷ $\mathrm{m}^{3}$ (KB1.b) và 5,0 tỷ $\mathrm{m}^{3}$ (KB1.c) thì hồ Lai Châu luôn đủ khả năng cắt lũ, hồ hoạt động an toàn, không bị vỡ đập.

Trường hợp tổng dung tích của các hồ chứa phía thượng lưu đến 5 tỷ $\mathrm{m}^{3}$, nếu hồ Lai Châu đang vận hành ở MNDBT thì mực nước lớn nhất (MNLN) đạt $+301,36 \mathrm{~m}$ thấp hơn mực nước dâng gia cường (MNDGC) là $1,5 \mathrm{~m}$, lưu lượng xả lớn nhất đạt khoảng $33.200 \mathrm{~m}^{3}$. Nếu hồ đang vận hành ở MNLTK, khi xảy ra sự cố MNLN đạt $302,57 \mathrm{~m}$ thấp hơn cao trình đỉnh đập $0,4 \mathrm{~m}$, lưu lượng lớn nhất khoảng $35.600 \mathrm{~m}^{3} / \mathrm{s}$, hồ Lai Châu sẽ gặp nguy hiểm.

Bảng 3. Thông số hồ Lai Châu khi vỡ đập ở thượng lưu

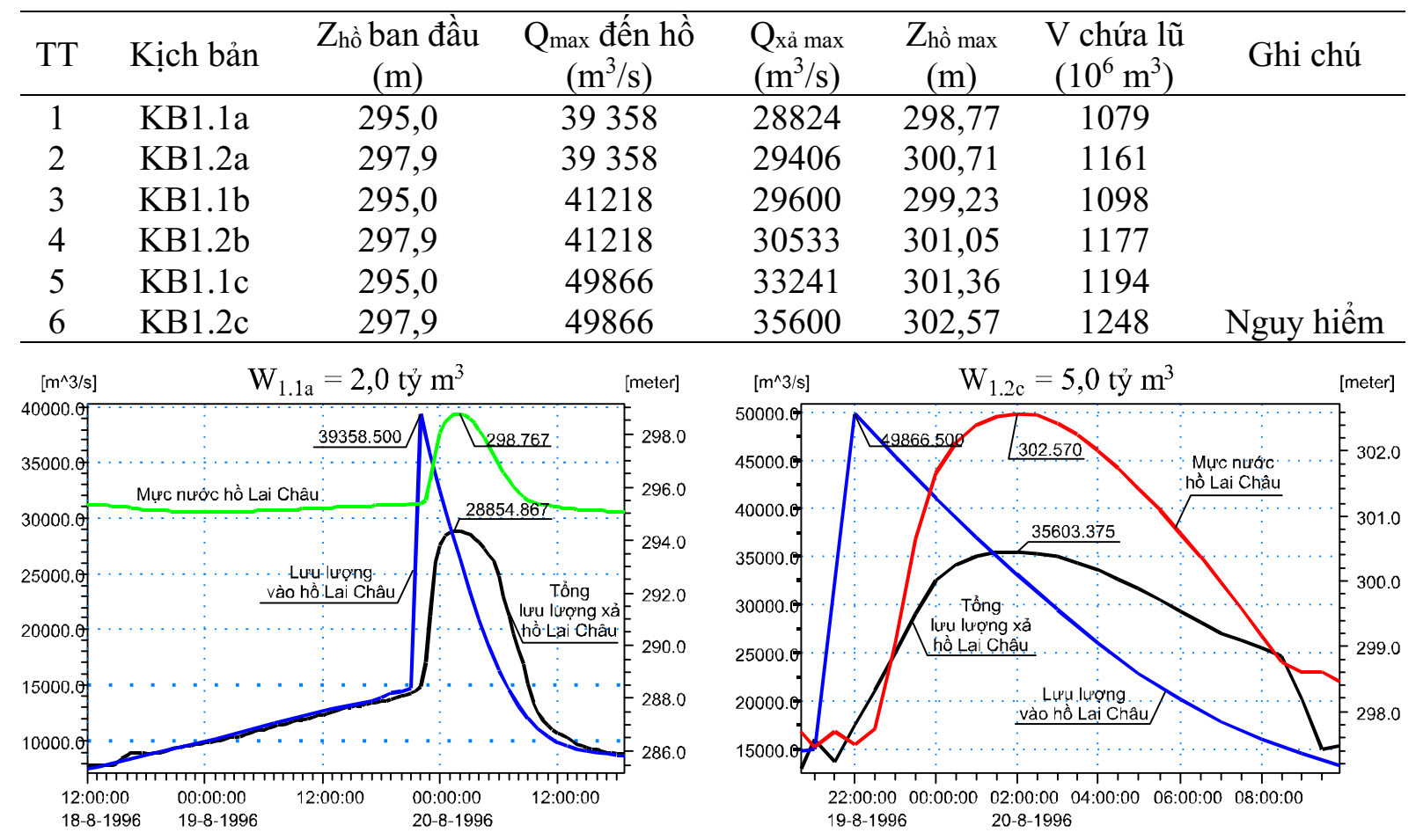

Hình 3. Quá trình lưu lượng đến hồ, lưu lượng xả và mưc nước tại hồ Lai Châu ưng với kịch bản vỡ đập thượng lưu 


\section{2. Đập hồ Lai Châu (KB2)}

Trường hợp chỉ vỡ đập Lai Châu thì tổng lượng lũ tối đa do vỡ đập gây ra về đến hồ Sơn La khoảng 1,5 tỷ $\mathrm{m}^{3}$, sẽ tác động tới hồ Sơn $\mathrm{La}$ và hồ Hòa Bình tùy theo tình trạng mực nước tại hai hồ, chi tiết thể hiện trên Bảng 3 , Hình 3 và Hình 4, cụ thể:

- Nếu 2 hồ đang vận hành ở MNTL, thì khi sự cố xảy ra, hồ Sơn La và hồ Hòa Bình đều cắt lũ hoàn toàn, 2 hồ hoạt động bình thường. MNLN tại 2 hồ đều thấp hơn MNDBT theo thứ tự là $10 \mathrm{~m}$ và $7 \mathrm{~m}$.

- Nếu 2 hồ đang vận hành ở MNDBT thì 2 hồ cũng đều đảm bảo khả năng cắt lũ và làm việc bình thường. MNLN tại hồ Sơn La đạt 221,5m cao hơn MNLTK 3,5m, tương ứng tại hồ Hòa Bình là $121,1 \mathrm{~m}$ và $1,1 \mathrm{~m}$.

- Nếu 2 hồ đang vận hành ở MNLTK, hồ Sơn La vẫn đủ khả năng cắt lũ và làm việc bình thường, MNLN tại hồ đạt 222,1m, thấp hơn MNLGC là $6,0 \mathrm{~m}$, lưu lượng xả lớn nhất khoảng $35.800 \mathrm{~m}^{3} / \mathrm{s}$. Tuy nhiên hồ Hòa Bình đạt tới giới hạn về làm việc an toàn. MNLN tại hồ đạt $122,5 \mathrm{~m}$ xấp xỉ cao trình đỉnh đập, gây nguy hiểm cho đập Hòa Bình.

Do đó cần vận hành điều tiết tích nước lại hệ thống để giảm nguy cơ cho đập Hòa Bình.

\section{Bảng 4. Thông số hồ Sơn La - Hòa Bình khi vỡ đập Lai Châu}

\begin{tabular}{|c|c|c|c|c|c|c|c|c|}
\hline \multirow[b]{2}{*}{ TT } & \multirow[b]{2}{*}{$\begin{array}{l}\text { Kịch } \\
\text { bản }\end{array}$} & \multirow{2}{*}{$\begin{array}{c}Z_{\text {hồ }} \\
\text { đang vận hành } \\
(\mathrm{m})\end{array}$} & \multirow{2}{*}{$\begin{array}{c}\text { Qmax đến hồ } \\
\text { SLa } \\
\left(\mathrm{m}^{3} / \mathrm{s}\right)\end{array}$} & \multicolumn{3}{|c|}{ Hồ Sơn La } & \multicolumn{2}{|c|}{ Hồ Hòa Bình } \\
\hline & & & & $\begin{array}{l}\text { Qxả max } \\
\left(\mathrm{m}^{3} / \mathrm{s}\right)\end{array}$ & $\begin{array}{c}Z_{\text {hồ max }} \\
\text { (m) }\end{array}$ & $\begin{array}{c}V_{\text {chứa lũ }} \\
\left(10^{6} \mathrm{~m}^{3}\right)\end{array}$ & $\begin{array}{l}\text { Qxả max } \\
\left(\mathrm{m}^{3} / \mathrm{s}\right)\end{array}$ & $\begin{array}{c}Z_{\text {hồ max }} \\
\text { (m) }\end{array}$ \\
\hline 1 & KB2.0 & MNTL & 94.202 & 21.728 & 204,86 & 1.871 & 21.921 & 110,14 \\
\hline 2 & KB2.1 & MNDBT & 94.133 & 35.484 & 221,53 & 1.538 & 34.113 & 121,10 \\
\hline 3 & KB2.2 & MNLTK & 70.099 & 35.871 & 222,10 & 1.035 & 36.296 & 122,53 \\
\hline
\end{tabular}
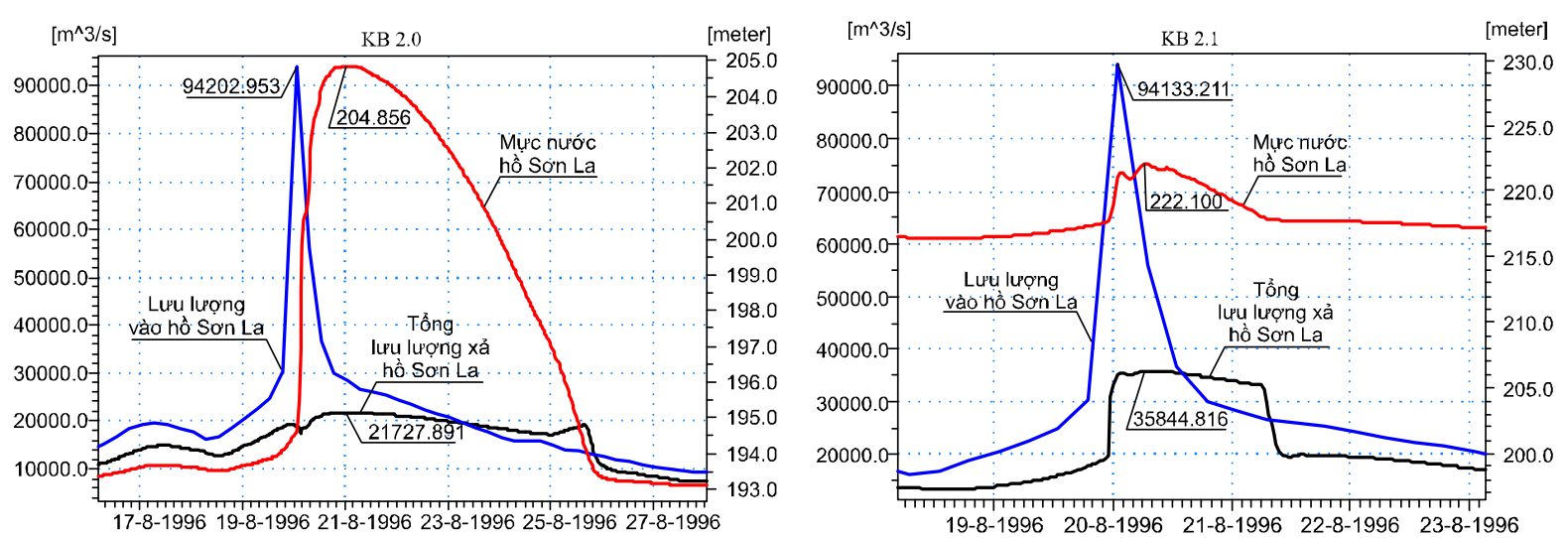

Hình 4. Quá trình lưu lượng đến, lưu lượng xả và mưc nước hồ Sơn La khi võ đập Lai Châu
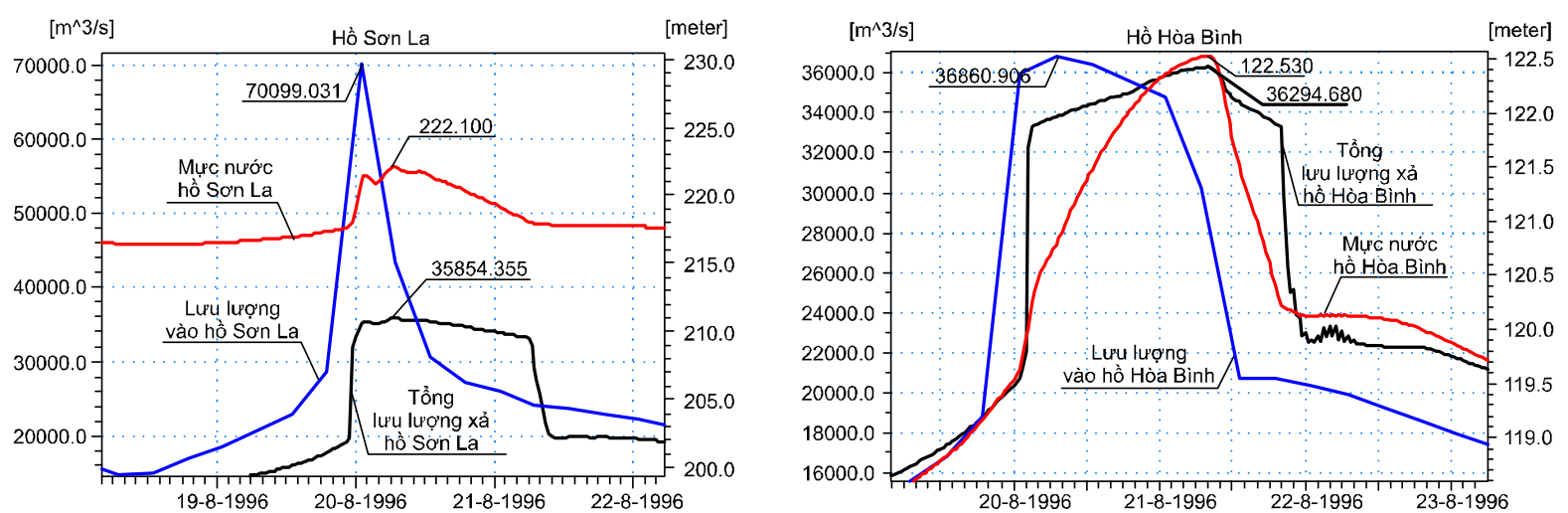

Hình 5. Quá trình lưu lượng đến, lưu lượng xả và mục nước khi vỡ đập Lai Châu KB2.2 


\section{3. Đập hồ Sơn La (KB6)}

Khi xảy ra sự cố vỡ đập Sơn La thì chỉ hồ Hòa Bình chịu tác động. Xem xét các kịch bản vỡ đập
Sơn La theo các chiều rộng và cao trình vết vỡ, tổng hợp kết quả thể hiện trên Bảng 5 . Kết quả cho thấy ở KB6.3 không gây vỡ đập Hòa Bình.

Bảng 5. Thông số hồ Hòa Bình khi xảy ra võ đập Sơn La

\begin{tabular}{|c|c|c|c|c|c|c|c|}
\hline TT & Kịch bản & $\begin{array}{c}Z_{\text {hồ ban đầu }} \\
\text { HB (m) }\end{array}$ & $\begin{array}{c}\text { Qmax đến hồ } \\
\left(\mathrm{m}^{3} / \mathrm{s}\right)\end{array}$ & $\begin{array}{l}\text { Qxả max } \\
\left(\mathrm{m}^{3} / \mathrm{s}\right)\end{array}$ & $\begin{array}{c}\begin{array}{c}\text { Zhồ max } \\
(\mathrm{m})\end{array} \\
\end{array}$ & $\begin{array}{c}\mathrm{V} \text { chứa lũ } \\
\left(\text { triệu m³ }{ }^{3}\right)\end{array}$ & Ghi chú \\
\hline 1 & KB6.0 (60m) & MNTL & 196.507 & 300.498 & 125,75 & - & Vỡ đập \\
\hline 2 & KB6.1 (60m) & MNDBT & 224.605 & 307.356 & 125,65 & - & Vỡ đập \\
\hline 3 & KB6.2 (20m) & MNBT & 34.928 & 31.494 & 119,66 & 515 & \\
\hline
\end{tabular}

Khi xem xét ảnh hưởng của sự cố vỡ đập Sơn La tới đập Hòa Bình, ngoài 03 kịch bản ở Bảng 5 , đã thiết lập các kịch bản tính toán chi tiết với các mực nước hồ khi vỡ, kích thước vết vỡ $(\mathrm{B}$, H) với mực nước hồ Hòa Bình khi vỡ, cụ thể:

- Về mực nước hồ Hòa Bình, khi vỡ hồ Sơn La là MNLN trong lũ chính vụ ở $101 \mathrm{~m}$ với mô hình lũ 500 năm.

- Về mực nước hồ Sơn La khi vỡ xét 05 trường hợp là: MNLN trong lũ chính vụ (194m), MNDBT (215m), MNLTK (217,8m), MNLN $(228 \mathrm{~m})$ và vỡ do tràn đỉnh khi mực nước vượt đỉnh đập ở cao trình $230 \mathrm{~m}$;

- Với chiều rộng lỗ vỡ: xét 04 trường hợp: $\mathrm{B}$ $=80,60,40$ và $20 \mathrm{~m}$;

- Về chiều sâu lỗ vỡ: xét 03 trường hợp là $\mathrm{D}$ $=2 / 3 \mathrm{H}, 1 / 2 \mathrm{H}$ và $1 / 3 \mathrm{H}$, với $\mathrm{H}$ là chiều cao lớn nhất của đập, tương ứng với cao trình vết vỡ lần lượt là $138 \mathrm{~m}, 163 \mathrm{~m}$ và $184,4 \mathrm{~m}$.

Tổ hợp tính toán cho 01 trường hợp vỡ đập Sơn La với mực nước hồ Hòa Bình khi vỡ lên đến 60 trường hợp, tiến hành tính toán mô phỏng, bằng cách loại trừ đã đi đến kết luận sau:

- Nếu hồ Sơn La xảy ra sự cố vỡ $60 \mathrm{~m}$ thì dù hồ Hòa Bình đang vận hành ở MNTL vẫn gặp nguy hiểm, hồ Hòa Bình không đủ dung tích cắt lũ sự cố. MNLN tại hồ Hòa Bình đạt 125,7m, cao hơn đỉnh đập $2,7 \mathrm{~m}$ gây tràn đỉnh, gây vỡ đập Hòa Bình.

- Nếu hồ Sơn La vỡ 1 khoang (20m) tức lưu lượng xả qua tràn Sơn La chỉ là $3.600 \mathrm{~m}^{3} / \mathrm{s}$ bằng 1/10 năng lực xả của tràn, chỉ tương đương với vỡ đập Sơn La trong mùa khô thì hồ Hòa Bình vẫn đảm bảo khả năng cắt lũ, an toàn cho công trình. MNLN tại hồ Hòa Bình đạt 119,7m, thấp hơn MNLTK là $0,3 \mathrm{~m}$. Lưu lượng xả lớn nhất đạt $31.500 \mathrm{~m}^{3} / \mathrm{s}$. Tuy nhiên, thời gian xả lũ duy trì đến 8 ngày sẽ gây nên áp lực không nhỏ đối với đê điều của khu vực đồng bằng Bắc Bộ.

- Nếu vỡ hồ Sơn La và mực nước hồ Hòa Bình ở mực nước cao nhất mùa lũ theo quy trình vận hành liên hồ chứa $(101 \mathrm{~m})$ thì tùy theo mức độ vỡ, cho thấy:

+ Hồ Sơn La ở MNTL (194m) thì với kích thước vết vỡ có $\mathrm{B}<80 \mathrm{~m}$ không gây vỡ đập Hòa Bình, khi đó mực nước hồ Hòa Bình lớn nhất là $116,07 \mathrm{~m}$.

+ Hồ Sơn La ở MNDBT (215m) và MNLTK $(217,8 \mathrm{~m})$ : với vết vỡ có $\mathrm{B}>60 \mathrm{~m}$ và chiều sâu vỡ $\mathrm{D}>2 / 3 \mathrm{H}$ sẽ gây vỡ đập Hòa Bình; với vết vỡ có cao trình trên $159 \mathrm{~m}(\mathrm{D}<1 / 2 \mathrm{H})$ và vết vỡ có $\mathrm{B}<40 \mathrm{~m}$ trở xuống không gây vỡ đập Hòa Bình, khi đó mực nước hồ Hòa Bình lớn nhất là $120,5 \mathrm{~m}$.

+ Khi hồ Sơn La ở mực nước ứng với điều tiết lũ PMF (228m) và tràn đỉnh: Với kích thước vết vỡ có $\mathrm{B}>60 \mathrm{~m}$, chiều sâu vỡ $\mathrm{D}>2 / 3 \mathrm{H}$ và lỗ vỡ có $B>80 \mathrm{~m}, \mathrm{D}>2 / 3 \mathrm{H}$ sẽ gây vỡ đập Hòa Bình; Với cao trình vết vỡ trên $159 \mathrm{~m}$ (vỡ $1 / 2 \mathrm{H}$ ) khi vỡ $\mathrm{B}<60 \mathrm{~m}$ và vết vỡ có chiều rộng từ $40 \mathrm{~m}$ trở xuống không gây vỡ đập Hòa Bình.

\subsection{Kịch bản võ đập trên nhánh Nậm Mu (KB3)}

Trên nhánh Nậm Mu có 02 hồ chứa là hồ Bản Chát và hồ Huội Quảng. Khi xảy ra vỡ đập trên nhánh Nậm Mu chỉ ảnh hưởng đến hồ Sơn $L a$ và hồ Hòa Bình. Khi vỡ đập Bản Chát luôn gây vỡ Huội Quảng do đó nghiên cứu chỉ phân tích đánh giá khi vỡ đập Bản Chát tác động tới các hồ hạ lưu (hồ Sơn La và Hòa Bình). Kết quả tính toán 
thể hiện trên Bảng 5, Hình 5 và Hình 6 cho thấy:

- Nếu 2 hồ Sơn La, Hòa Bình đang vận hành ở MNTL thì 2 hồ đủ khả năng cắt lũ, hồ hoạt động bình thường. MNLN tại hồ Sơn La đạt 209,7m thấp hơn MNDBT khoảng 5,5m, tương ứng tại hồ Hòa Bình là $113,2 \mathrm{~m}$ và $4,8 \mathrm{~m}$, lưu lượng lớn nhất xả về hạ du đạt $24.200 \mathrm{~m}^{3} / \mathrm{s}$.

- Nếu 2 hồ đang vận hành từ MNDBT trở lên thì MNLN của hồ Sơn La đạt 223,8m, vượt MNLTK khoảng $5,8 \mathrm{~m}$, thấp hơn MNDGC khoảng 4,3m. Hồ Sơn La đảm bảo cắt được đỉnh lũ, vận hành xả lũ bình thường, không bị vỡ đập. Tuy nhiên, MNLN tại hồ Hòa Bình đạt $121,7 \mathrm{~m}$ (với trường hợp hồ đang vận hành ở MNDBT), cao hơn MNLTK $1,5 \mathrm{~m}$ và là $123,1 \mathrm{~m}$ (với trường hợp hồ ở MNLTK), hồ Hòa Bình đạt ranh giới không thể tích thêm, dòng chảy xấp xỉ tràn đỉnh đập, nguy cơ mất an toàn cho đập Hòa Bình. Lưu lượng lớn nhất xả về hạ du đạt $37.000 \mathrm{~m}^{3} / \mathrm{s}$. Do đó, kịch bản này có thể điều tiết nâng tích lũ tại hồ Sơn La để giảm khả năng vỡ đập Hòa Bình.

Bảng 6. Thông số hồ Son La - Hòa Bình khi vỡ đập trên nhánh Nậm Mu

\begin{tabular}{ccccccccc}
\hline TT & $\begin{array}{c}\text { Kịch } \\
\text { bản }\end{array}$ & $\begin{array}{c}\text { Z hồ đang vận Qmax đến hồ } \\
\text { hành }(\mathrm{m})\end{array}$ & $\begin{array}{c}\text { SLa } \\
\left(\mathrm{m}^{3} / \mathrm{s}\right)\end{array}$ & $\begin{array}{c}\text { Qxả max } \\
\left(\mathrm{m}^{3} / \mathrm{s}\right)\end{array}$ & $\begin{array}{c}\text { Hồ Sơn La } \\
\text { Zhồ max } \\
(\mathrm{m})\end{array}$ & $\begin{array}{c}\mathrm{V}_{\text {chúa lũ }}\left(10^{6} \mathrm{~m}^{3}\right) \\
\left(\mathrm{m}^{3} / \mathrm{s}\right)\end{array}$ & $\begin{array}{c}\text { Hồ Hòa Bình } \\
(\mathrm{m})\end{array}$ \\
\hline 1 & KB3.0 & MNTL & 75996 & 26018 & 209,65 & 2779 & 24202 & 113,24 \\
2 & KB3.1 & MNDBT & 64560 & 36485 & 223,80 & 1915 & 34496 & 121,68 \\
3 & KB3.2 & MNLTK & 65534 & 37023 & 223,79 & 1466 & 37641 & 123,15 \\
\hline
\end{tabular}
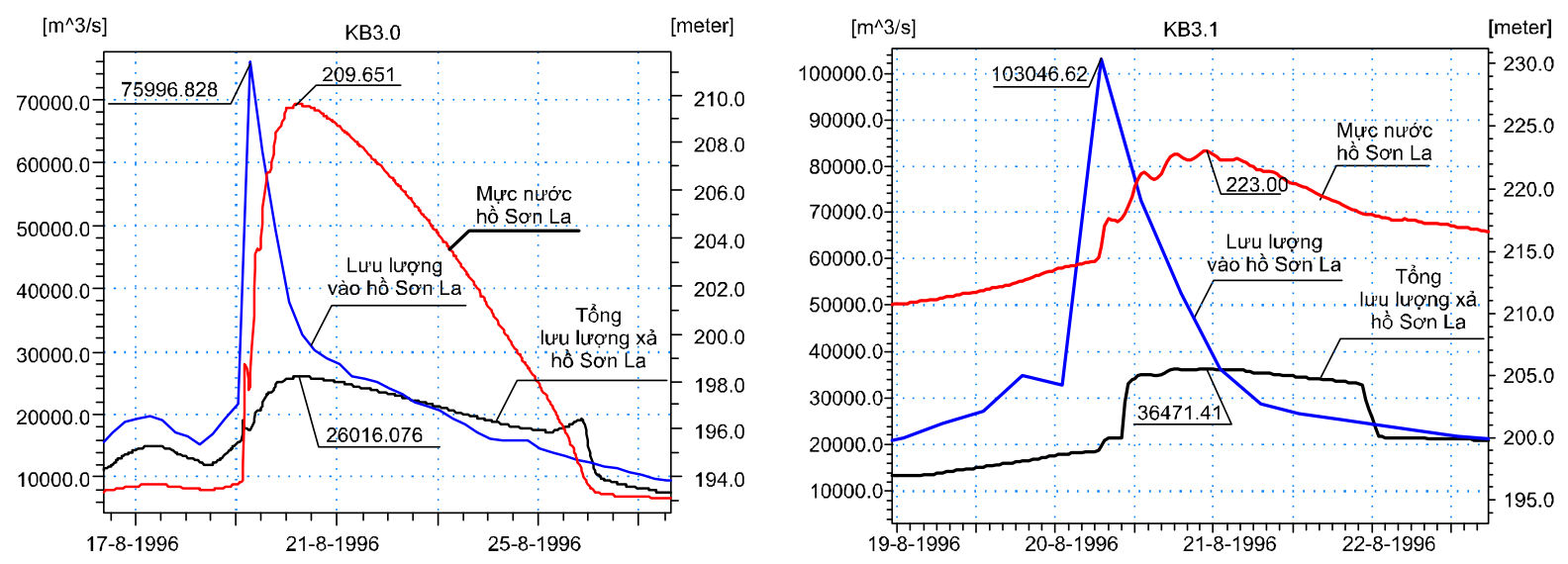

Hình 6. Kết quả cắt lũ của hồ Sơn La khi vỡ đập nhánh Nậm Mu
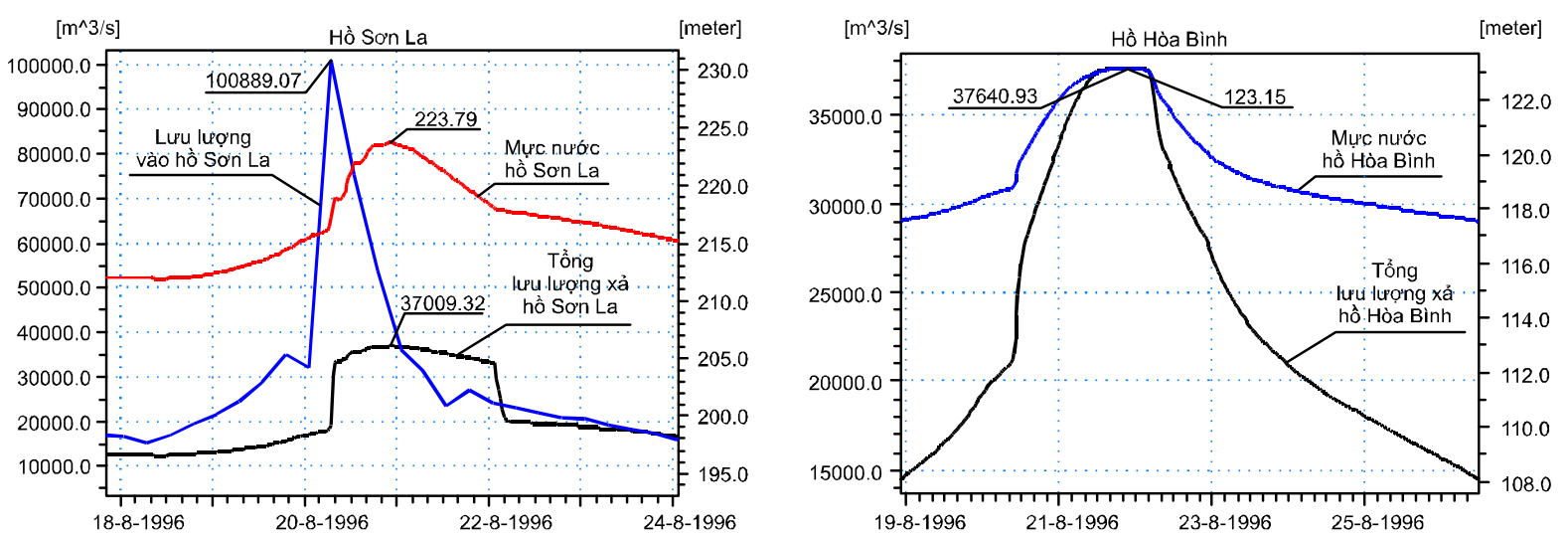

Hình 7. Kết quả cắt lũ của hồ khi vỡ đập trên nhánh Nậm Mu - KB3.2 


\section{BÀI BÁO KHOA HỌC}

\subsection{Kịch bản võ̃ đập trên nhánh Nậm Chiến (KB5)}

Trên nhánh Nậm Chiến có 2 hồ chứa là Nậm Chiến 1 và Nậm Chiến 2. Đây là hai hồ chứa nhỏ với tổng dung tích ứng với MNDBT là
158 triệu $\mathrm{m}^{3}$, tổng dung tích tính đến cao trình đỉnh đập của cả hai hồ khoảng 191 triệu $\mathrm{m}^{3}$. Khi xảy ra sự cố trên nhánh Nậm Chiến chỉ ảnh hưởng đến hồ Hòa Bình.

Bảng 7. Thông số hồ Hòa Bình khi xảy ra vỡ đập trên nhánh Nậm Chiến

\begin{tabular}{|c|c|c|c|c|c|c|c|}
\hline TT & Kịch bản & $\begin{array}{l}\text { Zhồ ban đầu } \\
\text { (m) }\end{array}$ & $\begin{array}{c}\text { Qmax đến hồ } \\
\left(\mathrm{m}^{3} / \mathrm{s}\right)\end{array}$ & $\begin{array}{l}Q_{\text {xả } \max } \\
\left(\mathrm{m}^{3} / \mathrm{s}\right)\end{array}$ & $\begin{array}{c}Z_{\text {hồ max }} \\
\text { (m) }\end{array}$ & $\begin{array}{c}V_{\text {chứa lũ }} \\
\text { (triệu m³ }{ }^{3} \text { ) }\end{array}$ & Ghi chú \\
\hline 1 & KB5.0 & MNTL & 21.086 & 20.522 & 108,02 & 1120 & \\
\hline 2 & KB5.1 & MNDBT & 23.393 & 23.754 & 117,53 & 102 & \\
\hline 3 & KB5.2 & MNLTK & 27.324 & 25.813 & 119,63 & - & \\
\hline
\end{tabular}

Kết quả tính toán thể hiện trên Bảng 6 , cho thấy: lưu lượng lũ do sự cố trên nhánh Nậm Chiến là rất nhỏ so với dung tích điều tiết của hồ Hòa Bình. Với lưu lượng xả điều tiết lớn nhất của Hòa Bình đạt $25.800 \mathrm{~m}^{3} / \mathrm{s}$ nên nếu xảy ra sự cố trên nhánh Nậm Chiến, mực nước tại hồ Hòa Bình vẫn gần như giữ nguyên như mực nước ban đầu. Hồ Hòa Bình hoàn toàn làm việc bình thường.

3.5. Kịch bản xảy ra đồng thời sụ cố trên nhánh Lai Châu, nhánh Nậm Mu và Nậm Chiến (KB7)

Khi xảy ra sự cố đồng thời trên nhánh Lai Châu, Nậm Mu và Nậm Chiến sẽ gây tác động lớn tới hồ Sơn La và hồ Hòa Bình. Tổng hợp kết quả tính toán thể hiện trên Bảng 7 và Hình 7 , kết quả cho thấy:

- Nếu 2 hồ (hồ Sơn La và hồ Hòa Bình) đều năng cắt lũ sự cố. MNLN tại hồ Sơn La đạt 215,6m xấp xỉ MNDBT, tại hồ Hòa Bình tương ứng là $116 \mathrm{~m}$ thấp hơn MNDBT 1,0m. Lưu lượng xả lớn nhất về hạ du đạt $26,500 \mathrm{~m}^{3} / \mathrm{s}$, mực nước tại Hà Nội là $13,37 \mathrm{~m}$ đảm bảo an toàn cho hạ lưu.

- Nếu 2 hồ đang vận hành xả lũ ở MNDBT, thì hồ Sơn La vẫn cắt được lũ nhưng MNLN đạt 228,1m xấp xỉ vượt MNDGC. Tại hồ Hòa Bình MNLN đạt $123,9 \mathrm{~m}$ bắt đầu tràn trên đỉnh đập, nguy cơ cao gây vỡ đập trong khi đã xả lũ đến mức độ lớn nhất có thể, lưu lượng là $38.196 \mathrm{~m}^{3} / \mathrm{s}$.

- Nếu 2 hồ đang vận hành ở MNLTK, thì cả 2 đều không có khả năng cắt lũ sự cố và cũng không thể điều tiết hệ thống. MNLN tại 2 hồ đều vượt đỉnh đập khoảng $1,5 \mathrm{~m}$, cả hai hồ đều gặp nguy cơ cao bị vỡ, lưu lượng xả lớn nhất về hạ du đạt trên $282.000 \mathrm{~m}^{3} / \mathrm{s}$. đang vận hành ở MNTL thì cả 2 hồ đều đủ khả

Bảng 8. Thông số hồ Son La - Hòa Bình khi xảy ra sụ cố đồng thời trên các nhánh Lai Châu, Nậm Mu và Nậm Chiến

\begin{tabular}{|c|c|c|c|c|c|c|c|c|}
\hline \multirow[b]{2}{*}{ TT } & \multirow[b]{2}{*}{ Kịch bản } & \multirow{2}{*}{$\begin{array}{l}\text { Z hồ đang } \\
\text { vận hành } \\
\text { (m) }\end{array}$} & \multicolumn{3}{|c|}{ Hồ Sơn La } & \multicolumn{2}{|c|}{ Hồ Hòa Bình } & \multirow[t]{2}{*}{ Ghi chú } \\
\hline & & & $\begin{array}{c}\text { Qmax đến } \\
\left(\mathrm{m}^{3} / \mathrm{s}\right)\end{array}$ & 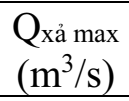 & $\begin{array}{c}Z_{\text {hồ max }} \\
(\mathrm{m})\end{array}$ & $\begin{array}{l}\text { Qxả max } \\
\left(\mathrm{m}^{3} / \mathrm{s}\right)\end{array}$ & $\begin{array}{c}\begin{array}{l}\text { Zhồ max } \\
(\mathrm{m})\end{array} \\
\end{array}$ & \\
\hline 1 & KB7.0 & MNTL & 102930 & 31008 & 215,60 & 26454 & 116,01 & \\
\hline 2 & KB7.1 & MNDBT & 136631 & 39987 & 228,06 & 38196 & 123,87 & Tràn đỉnh \\
\hline 3 & KB7.2 & MNLTK & 119979 & 49972 & 229,70 & 282503 & 124,48 & Vỡ đâp \\
\hline
\end{tabular}




\section{Kết luận}

- Với trường hợp hồ Sơn La và Hòa Bình đang ở MNLTK $(217,83 \mathrm{~m}, 120 \mathrm{~m})$ khi xảy ra các sự cố vỡ đập trên các nhánh riêng lẻ Lai Châu, Nậm Mu sẽ không gây nguy hiểm cho hồ Sơn La. Khi vỡ đập riêng lẻ trên nhánh Lai Châu hoặc Nậm Chiến, sẽ không gây nguy hiểm cho hồ Hòa Bình, hồ vẫn có khả năng điều tiết để giảm thiểu thiệt hại cho hạ du. Riêng trường hợp xảy ra sự cố vỡ đập Bản Chát trên nhánh Nậm $\mathrm{Mu}$, kéo theo vỡ đập Huội Quảng, gây nguy cơ vỡ đập Hòa Bình do tràn đỉnh.

- Với trường hợp hồ Sơn La và Hòa Bình ở MNDBT trở xuống, các sự cố vỡ đập thượng lưu trên các nhánh riêng lẻ không gây nguy hiểm cho hồ hạ lưu, hai hồ này đảm bảo điều tiết.

- Trong 08 nhóm kịch bản tính toán khi võ các đập thượng lưu, các trường hợp sau xảy ra vỡ đập hạ du:

+ Nếu sự cố vỡ hồ Nậm Chiến 1 thì hồ Nậm Chiến 2 sẽ bị vỡ;

+ Nếu sự cố vỡ hồ Bản Chát thì hồ Huội Quảng sẽ bị vỡ;

+ Khi sự cố vỡ toàn bộ hệ thống hồ ở thượng lưu Lai Châu với trường hợp tính toán gộp chung thành 1 hồ có dung tích 5 tỷ, hồ Lai Châu có nguy cơ bị vỡ khi ở lớn hơn MNLTK;

+ Nếu sự cố vỡ đồng thời cả 3 hồ ở thượng lưu Sơn La, Sơn La bị vỡ khi ở mực nước lớn hơn MNLTK;

+ Khi xảy ra sự cố các đập đồng thời trên các nhánh Lai Châu, Nậm Mu, Nậm Chiến: có nguy cơ cao mất an toàn đập, khi hai hồ ở MNDBT trở lên.

+ Nếu sự cố vỡ hồ Sơn La và mực nước ở hồ Hòa Bình ở mực nước cao nhất mùa lũ theo quy trình vận hành liên hồ chứa $(101 \mathrm{~m})$ thì tùy theo mức độ vỡ (bề rộng vết vỡ, cao trình vỡ) mới gây nguy hiểm cho hồ Hòa Bình.

+ Nếu sự cố vỡ hồ Sơn La ở MNDBT (215m) và $\operatorname{MNLTK}(217,8 \mathrm{~m})$, có vết vỡ $\mathrm{B}>60 \mathrm{~m}$ và chiều sâu vỡ $\mathrm{D}>2 / 3 \mathrm{H}$ sẽ gây vỡ đập Hòa Bình và ngược lại.

+ Nếu sự cố vỡ hồ Sơn La ở mực nước ứng với điều tiết lũ PMF $(228 \mathrm{~m})$ và tràn đỉnh: Với kích thước vết vỡ có $\mathrm{B}>60 \mathrm{~m}$, chiều sâu vỡ $\mathrm{D}>$ $2 / 3 \mathrm{H}$ và lỗ vỡ có $\mathrm{B}>80 \mathrm{~m}, \mathrm{D}>2 / 3 \mathrm{H}$ sẽ gây vỡ đập Hòa Bình; Với cao trình vết vỡ trên $159 \mathrm{~m}$ (vỡ $1 / 2 \mathrm{H}$ ) khi vỡ $\mathrm{B}<60 \mathrm{~m}$ và vết vỡ có chiều rộng từ $40 \mathrm{~m}$ trở xuống không gây vỡ đập Hòa Bình.

Kết quả tính toán trên là trường hợp khi có sự cố vỡ đập các hồ còn lại vẫn vận hành theo quy trình, không vận hành trong chế độ tích nước khi có sự cố, nên có trường hợp hồ dưới bị uy hiếp, xả với lưu lượng lớn, nhưng hồ trên vẫn chưa làm việc hết năng lực. Do vậy cần điều tiết toàn hệ thống khi có lũ vỡ đập để giảm nguy cơ cho đập phía dưới và vùng hạ du.

Đây là kết quả nghiên cứu đầy đủ nhất về các kịch bản và nguy cơ xảy ra sự cố vỡ đập với hệ thống bậc thang hồ chứa trên sông Đà khi có sự cố vỡ đập. 


\title{
BÀI BÁO KHOA HỌC
}

\section{Tài liệu tham khảo}

1. Bhawan, J.V. (1997), Dambreak study of Barna dam, National Institute of Hydrology, India.

2. Le Tran Chuong, Le Van Thuan, Vu Anh Khoa (2001), Dam Breach Flood Wave Simulation in Reservoir Cascade of Lai Chau-Son La-Hoa Binh. Proceedings. International Symposium on Achivements of IHP-V in Hydrological Research, Hanoi.

3. Lê Văn Nghị và cs. (2019), Mô hình vật lý vỡ đập, NXB. Khoa học và Kỹ thuật.

4. Nguyễn Văn Hạnh, Nguyễn Đức Diện (2003), Nghiên cứu lũ và lũ do võ đập trong hệ thống sông Hồng - sông Thái Bình, Hợp phần thuộc dự án DANIDA, Hà Nội, Việt Nam.

5. Trần Đình Hợi, Trần Quốc Thưởng, Lê Văn Nghị (2004), Nghiên cứu bài toán mô hình thủy lục vỡ đập công trình thủy điện Sơn La phục vu thiết kế và vận hành an toàn công trình, Đề tài cấp Bộ.

6. Lê Văn Nghị và cs. (2019), Nghiên cưu đánh giá rủi ro đối với thượg hạ du khi xảy ra sụ cố các đập trên hệ thống bậc thang thủy điện sông Đà, Đề tài KC08.22/11-15, Hà nội.

7. Trần Thục (2003), Tính toán thuỷ lực trong trường hợp giả sủ võ đập Hoà Bình và Sơn La, Tạp chí Khí tượng thuỷ văn 2(506)/2003.

8. Hướng dẫn mô hình MIKE (DHI-2009), MIKE 11. Reference Manual, MIKE Zero. Reference Manual.

9. Thủ tướng Chính phủ “Quy trình vận hành trên hệ thống sông Hồng” Ban hành theo Quyết định 1622/QĐ-TTg ngày 17/9/2015.

\section{RISK ASSESSMENT FOR TERRACED RESERVOIRS SYSTEM ON DA RIVER IN CASE OF DAM FAILURE \\ Le Van Nghi ${ }^{1}$}

${ }^{1}$ Key Laboratory of River and Coastal Engineering

\begin{abstract}
Da river is the largest branch of the Red River system, with the most potential hydropower in the country. In the Da river basin, 7 large reservoirs have been built, which has 3 the largest hydropower plants in Vietnam: Laichau, Sonla and Hoabinh. These terraced reservoirs have an important task in flood control, water supply, and power generation, but at the same time each construction adds more potential risks to the lower level system and works if encountered trouble. The paper presents the results of a risk assessment study for the system of the Da river terraced reservoirs according to some dam break incidents, using hydraulic numerical model. Evaluation results will help managers, planners and researchers to reasonably operate the reservoirs of Da river as well as to ensure safety for the Red River downstream.
\end{abstract}

Keywords: Numerical model, Terraced reservoirs, Da river, Dam break. 